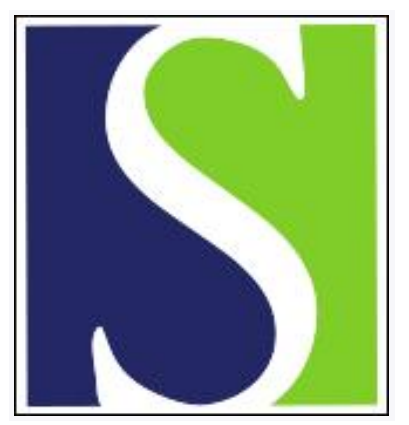

Scand J Work Environ Health 2020;46(1):105-109

https://doi.org/10.5271/sjweh.3851

Published online: 05 Sep 2019, Issue date: 01 Jan 2020

Public health and evidence-informed policy-making: The case of a commonly used herbicide

by Vainio $\mathrm{H}$

Affiliation: Department of Environmental and Occupational Health, Faculty of Public Health, Kuwait University, P.O. Box 24923, Safat, 13110 Kuwait. harri.vainio@hsc.edu.kw

Key terms: commentary; conflict of interest; evidence-informed policy-making; glyphosate; herbicide; IARC; Monsanto; pesticide; public health; Roundup

This article in PubMed: www.ncbi.nlm.nih.gov/pubmed/31486846 


\title{
Public health and evidence-informed policy-making: The case of a commonly used herbicide
}

\begin{abstract}
"Despite substantial evidence that Roundup weed killer is safe and non-carcinogenic if used properly, a federal judge last week appointed attorney Kenneth Feinberg to oversee court-mandated settlement talks between Bayer $A G$ (the company that owns Roundup's producer, Monsanto) and plaintiffs who claim that the product caused their non-Hodgkin's lymphoma." (1).
\end{abstract}

For almost half a century, the International Agency for Research on Cancer (IARC) has run a Monographs programme, which has been the premier global resource for the identification of agents that cause cancer (2). The Monographs apply rigorous procedures for the scientific review and evaluation of carcinogenic hazards by independent experts, free from conflict of interest. Since publishing Monograph conclusions on some pesticides (3), the IARC has been subject to intense efforts to undermine its evaluation and the whole organization. The conclusion in March 2015 that glyphosate is "probably carcinogenic to humans" in addition to being genotoxic and carcinogenic in animals led to unprecedented lobbying by the herbicide producer Monsanto, and resulted in high profile court cases in the USA (4).

Monsanto's tactic has been to discredit the glyphosate evaluation, the scientists involved, the Monograph programme and the IARC in general (see the Monsanto papers, 5-7). This has manifested in an orchestrated exercise of damage-generation played out through a coordinated and repetitive misrepresentation of facts, planned already before the March 2015 meeting took place (5). The once-confidential Monsanto papers have exposed the "cozy connections" between the company leadership, some regulatory agencies, and the media to undermine and discredit the actions and evaluation report of the IARC. They have revealed company scientists casually discussing "ghost-writing" scientific papers and suppressing science that conflicts with corporate assertions of Roundup's safety. The Monsanto documents demonstrate the company's manipulation of science and regulators, which may have reflected on the conclusions around the safety of the herbicide (6-8).

\section{Evaluations of pesticides}

IARC has evaluated more than 60 of the 100 s of active ingredients in pesticide formulations, less than 12 of which have been formally evaluated as either group
1 (human carcinogens) or $2 \mathrm{~A}$ (probable human carcinogens) (2). Some of these, such as dichlorodiphenyltrichloromethane (DDT) and lindane, have now been banned in most countries.

The evaluation of pesticides typifies the problems associated with research and regulation of commonly used consumer and agricultural products. IARC's evaluation of "probably carcinogenic to humans" (group 2A) is the second strongest category of evidence in a fourtier scale. The industry reaction to the evaluation of glyphosate was not foreseen. The two other chemicals evaluated in the same meeting as probably carcinogenic to humans (group 2A), diazinon and malathion, engendered no public debate.

If a widely used herbicide turns out to be a putative cancer-causing chemical, the consequences for the producer can be potentially devastating. In May 2019, a court in California ordered Bayer AG to pay US\$2 billion to a couple who claimed their cancers were caused by years of using Roundup. This was the third legal loss since August 2018 for Bayer AG, which has seen its market value plummet to $\$ 52$ billion, cut nearly in half since it acquired Monsanto a year ago (9). More than 13000 similar claims have been lodged (1).

\section{How is the herbicide used 'properly'?}

Ever since Monsanto introduced its line of Roundup weed-killers in 1974, the products have been touted as extremely safe. The company's statement that glyphosate is "safe and non-carcinogenic if used properly" is difficult to interpret in practice: even if you were dealing with a putative carcinogen, the cancer risk is not realized if you are not exposed to the agent, ie, the product is "safe if used properly".

So what is the "proper use" of a herbicide? One would assume it is use that is according to instructions on the label and guidance given by the producer. But when spreading the weed killer, it may be difficult to 
avoid human exposure. The occupational exposure in agriculture is likely to carry the most significant risk, followed by environmental exposures and risks to the consumers. Occupational exposure of glyphosate may occur via inhalation, dermal contact, and/or ocular contact during manufacture, transport, use and disposal. The absorption through skin is a real possibility. The general population may be exposed to glyphosate through dermal contact with consumer products, crops, foliage, or soils containing residues of this chemical. As a result of the widespread usage, glyphosate is present at low levels in a wide range food items (10).

The health risk is dependent on the level of exposure - it is the dose which makes the poison. The more intensively you are exposed, the longer the exposure period, and the higher the risk. The IARC evaluation does not take a position on the quantity or acceptability of the risk. This is not the task of the Agency but rather that of national decision-makers. The IARC evaluation constitutes a 'hazard evaluation' step in the risk assessment and management process - it is followed by an exposure analysis, quantitative risk assessment and risk-benefit analysis done in the policy-making process usually at the national regulatory level.

\section{What is evidence-informed policy-making?}

Simply put, evidence-informed policy is when decision-makers use the best available evidence to guide policy and regulations. Policy-makers in contemporary societies want to use evidence to make well-informed decisions, and scientists and scientific organizations are expected to provide the best evidence for their attention. A good supply of quality evidence and a healthy independent research community that is producing robust policy-relevant research is thus needed.

A common issue is how to synthesize evidence that is more often than not sparse, full of gaps, and difficult to manage, to do it in a transparent fashion and to transfer the conclusions into reasonable policy decisions.

Evidence-informed policy-making can be undermined by the manipulation or selective use of data, which is often driven by vested interests $(11,12)$. The point is well-taken in public health, with tobacco a prime example (13). Analysis of millions of internal tobacco industry documents has revealed the multiple strategies via which the tobacco industry has sought to, and often successfully, undermine public health policies (14). Tobacco is clearly an exceptional product; no other consumer product kills two in three users when used exactly as intended (15). But there is little to suggest that, as a corporate actor, "Big Tobacco" differs fundamentally from, eg., "Big Booze" or "Big Food" $(16,17)$. Disruptions of the scientific process and creation of doubt may lead to delays in translating evidence into policy, with the potential to cost lives (11). Consequently, scientists, toxicologists, epidemiologists, other health professionals, patients and populations have a collective responsibility not simply to be originators of scientific data but to be scrutinizers of their use, thereby protecting the interests of the many rather than the few.

\section{Some national regulatory bodies have asserted that glyphosate poses no public risk}

The regulatory European Food Safety Authority (EFSA) and the US Environmental Protection Agency (EPA) have asserted that glyphosate poses no public risk. But the US Agency for Toxic Substances \& Disease Registry (ATSDR) has joined IARC in concluding that there is a potential cancer hazard with glyphosate and its formulations $(3,18)$. Several of the national health agencies in Europe, the USA, and elsewhere have sided with the interpretation of the producer - that the herbicide is safe when used properly. Campaigns against glyphosate are the strongest in the European Union, where member nations in 2017 only narrowly reapproved a 5-year authorization of the compound.

\section{Why this discrepancy?}

As stated by Alfredo Morabia in a recent American Journal of Public Health editorial, "to defend what they perceive as in their best interests, some corporations not only pressure governmental agencies, they fight them." (19) In the same journal, Jonathan Samet (20) describes how Monsanto has moved extremely aggressively against the science, the unpaid expert volunteers, and institutions such as the IARC. The independent assessment of risk by "unpaid expert volunteers cannot be replaced by reviews from scientists paid by the industry." (20) The risk management may go beyond scientific evidence and imply the contribution of social values and social theory, in contrast to independent risk assessment (21).

Through the Monsanto papers, it has become clear that while the company was not willing to conduct the proposed long-term product safety studies (eg, a longterm carcinogenicity bioassay on the formulated product), the company spent millions of dollars on secretive PR campaigns - including $\$ 17$ million in one year after the IARC evaluation had been published - to finance "ghost-written" studies and editorials aimed at discrediting independent scientists whose work had found dangers with Monsanto's pesticides. These controversial "ghost-written" papers have been available as evidence for non-carcinogenicity in the regulatory processes.

The EFSA has had apparent links with the pesticides industry, eg, through organizations such as International Life Sciences Institute (ILSI). A recent analysis of ILSI's 
activities concluded that the organisation "should be regarded as an industry group - a private body - and regulated as such, not as a body acting for the greater good" (22). While ILSI purports to be working for health and wellbeing of populations internationally, the authors of the analysis "identified overt attempts by ILSI to influence individuals, positions, and policy, both at national and international levels, alongside clear statements that ILSI's corporate members deploy it as a tool to thwart policies or leaders who are hostile to their interests." (22)

It is noteworthy that the chair of ILSI's Board of Trustees chaired the UN's joint Food and Agriculture Organization (FAO)/World Health Organization (WHO) meeting on glyphosate that found the herbicide to be "probably not carcinogenic to humans" (23). This was of great interest to ILSI major donors Monsanto and its industry representative CropLife International. The final meeting report included no conflict of interest statement, even though ILSI Europe had received donations worth more than US\$1 million (from Monsanto and Croplife International) (23).

\section{The EU hazard-based approach}

Individuals connected to ILSI continue to play a role in the EU's advisory mechanisms. These activities have contributed to recommendations such as a slew of industry positions on pesticides (23). Their report recommended inter alia that the EU's precautionary hazard -based approach should be re-examined to determine whether it is delivering the intended levels of protection. The report recommended replacing current rules that outlaw any product that could harm with a US-style concept of "acceptable risk" (24). Unique to Europe, "the hazards approach" means that any pesticide found to be carcinogenic, mutagenic, reprotoxic, persistent or bioaccumulative, occurring even at low levels, can be regulated or even banned.

Monsanto has been careful to ensure that the US EPA is on board (25). Ominously, EPA staff has been accused of collusion with Monsanto to downgrade the health hazards of glyphosate (26). Jess Rowland, formerly a manager in the EPA's pesticide division, is said to have boasted in an April 2015 conversation with a Monsanto regulatory affairs manager that "If I can kill this, I should get a medal" (27). In October 2015, the EPA's Cancer Assessment Review Committee (CARC), chaired by Rowland, produced an internal report claiming that glyphosate, contrary to the IARC findings, was "not likely to be carcinogenic to humans" (28).

The US EPA has recently reconfirmed its position of "no risks to public health when glyphosate is used in accordance with the its current label" and "glyphosate is not a carcinogen" (29).

Health risks are not the only concern with glypho- sate. The vast increase in its use has also caused a substantial increase in glyphosate-tolerant weeds, dubbed "superweeds" by some (30).

\section{Conflict of interests}

As the proverb states: "Who pays the piper, calls the tune", most of us understand what is meant by "conflict of interest". The professional ethics codes have paid attention to conflicts of interest since 1970s, with better or worse consequences. Connected with conflict of interest, "duty of loyalty" is a term used in corporate law to describe a fiduciary's "conflict of interest". Accordingly, fiduciaries must put the corporation's interests ahead of their own (31). Indeed, the fiduciary responsibilities of all corporations require them to maximize their profits regardless of consequences to health, society, or the environment and thus to oppose policies that could reduce their profits (32). This obviously causes problems in evaluating evidence if the topic of evaluation - such as a particular pesticide - falls under the interest of the corporation.

Corporations defend their rights and their primary interests, which most often are financial ones. In the case of public health, the health of the population is the primary interest. In some situations, corporations have meddled in public policy-making on chemicals and topics where they have vested interests in terms of financial profits, trade and market shares. This all means a strong conflict of interest situation: the primary interests in public health are displaced by the interests of the corporations (21).

Corporations cannot be expected to assess impartially the potential toxicity of their own products. The independent creation of evidence requires specific procedures and skills necessary to draw conclusions based on the review and summary of a large body of evidence in order for it to be transparent and useful for policy decisions. As Morabia puts it: "IARC Monographs are an ingenious way to do exactly that" (19).

\section{Discussion}

Drawing conclusions on the causation of adverse health effects by environmental chemicals can have important societal consequences, leading to policy-making which can control, limit or even prevent the exposure to the pollutant through regulation and litigation. There are critical lessons to be learned from the Monsanto saga. The whole process of evidence-informed policy-making is under threat. The case of glyphosate is by no means over; further research is needed to cover the knowledge gaps, but this should be done independently and with full transparency. 
The IARC Monographs provide the scientific evaluation of the evidence based on comprehensive review of the scientific literature, but it remains the responsibility of individual governments and other international organizations to recommend, if any, regulations, legislation and other public health interventions. The IARC Monographs evaluate the hazard, but the societal decisions take also other factors into account while making the risk management decisions. The risk management philosophies for pesticides in various countries are different - in the EU, for example, the hazards (inherent properties) are emphasized while, in the US, the utilitarian acceptable risk approach prevails.

The active ingredients for pesticide formulations are under constant development. Sometimes the dominant role of one ingredient may have a damping effect in the innovation paths. This seems to have been the case with the weed-killing chemical glyphosate. The company which produces glyphosate has a central role in the weed-killer and the associated genetically modified tolerant crops market. Glyphosate dominates the field of weed killers worldwide: no compound with a new way of attacking weeds, or mode of action, has been commercialized for more than 30 years (9).

Glyphosate is at the center of a public herbicide debate. Cropping systems are currently very reliant on herbicides. If glyphosate is pulled out of the market, what are the alternatives? It is clear that companies need to ramp up their R\&D efforts to develop new candidate chemicals - or nonchemical alternatives - and new technologies for sustainable weed control, such as targeted spraying of herbicides directly into weeds, use of lasers, blades or electricity to kill weeds, are needed.

Evidence based on independent research provides the best tools to protect humans from harmful products, behaviors, and policies. Many responsible companies that market products that may have wide-spread exposure (such as pesticides) or potentially pose a risk to humans are collaborating internationally to gather the evidence. Instead of attacking the science, scientists, and science organizations and manipulating the media, such companies are working with the science community to secure human health and protect the environment.

\section{Disclosure statement}

In my past career, I served on the IARC Monographs program as a staff member from 1983 to the early 1990s. I have not been involved in the evaluation of glyphosate at any level. I currently have no employment links to the IARC or any financial interests in writing this commentary. While my spouse serves currently as the Director of IARC, she is in no way responsible for any part of the text. All the responsibility lies with me and me only.

\section{References}

1. Braceras JC. Rounding Up the Science Behind the Roundup Nuisance Litigation. Independent Women's Forum, May 28, 2019.

2. International Agency for Research on Cancer (IARC). Agents Classified by the IARC Monographs, Volumes 1-124. Available from: https://Monographs.iarc.fr/agents-classifiedby-the-iarc/ [Accessed May 30, 2019.]

3. Guyton KZ, Loomis D, Grosse Y, El Ghissassi F, BenbrahimTallaa L, Guha N et al. Carcinogenicity of tetrachlorvinphos, parathion, malathion, diazinon, and glyphosate. Lancet Oncol. 2015;16(5):490-1. https://doi.org/10.1016/S14702045(15)70134-8

4. Reuters. Monsanto ordered to pay $\$ 289$ million in Roundup cancer trial. The New York Times; 10 August 2018. Available from: https://www.nytimes.com/2018/08/10/business/ monsanto-roundup-cancer-trial.html. [Accessed May 30, 2019].

5. Monsanto. Exhibit 42 - IARC carcinogen rating of glyphosate preparedness and engagement plan. UCSF Library, Chemical Industry Documents. Available from: https://www.industrydocumentslibrary.ucsf.edu/chemical/ docs/\#id=xhmn0226. 2015. [Accessed May 31, 2019].

6. Horel S, Foucart S. The Monsanto Papers, Part 1 - Operation: Intoxication. Environmental Health News. Available from: https://www.ehn.org/monsanto-glyphosate-cancer-smearcampaign-250910888.html. 2017. [Accessed May 30, 2019].

7. Horel S, Foucart S. The Monsanto Papers, Part 2 - Reaping a bitter harvest. Environmental health News. Available from: https://www.ehn.org/monsanto-takes-on-world-healthorganization-2509721283.html. 2017. [Accessed May 30, 2019].

8. McHenry LB. The Monsanto Papers: poisoning the scientific well. Int J Risk Saf Med 2018;29(3-4):193-205. https://doi.org/10.3233/JRS-180028.

9. Stokstad E. Costly cancer lawsuits may spur search to replace world's most common weed killer. Science 2019;(May):22. Available from: https://www.sciencemag. org/news/2019/05/costly-cancer-lawsuits-may-spur-searchreplace-worlds-most-common-weed-killer

10. Food and Agriculture Organization (FAO) and World Health Organization. (WHO). Pesticides residues in food 2016. Special session of the joint FAO/WHO meeting on pesticide residues. FAO plant production and protection paper. Geneva: FAO and WHO; 2017;25(April). Available from: http://www.fao.org/3/a-i5693e.pdf

11. Michaels D. Doubt is their Product, How Industry's Assault on Science Threatens Your Health. $1^{\text {st }}$ edition ed., New York: Oxford University Press; 2008.

12. Pearce N. Corporate influences on epidemiology. Int $\mathbf{J}$ Epidemiol 2008 Feb;37(1):46-53. https://doi.org/10.1093/ ije/dym 270 .

13. Bero L. Implications of the tobacco industry documents 
for public health and policy. Annu Rev Public Health 2003;24:267-88. https://doi.org/10.1146/annurev. publhealth.24.100901.140813.

14. World Health Organization. Tobacco Industry Interference with Tobacco Control. Geneva: WHO; 2008. Available from: http://www.who.int/tobacco/resources/publications/ Tobacco\%20Interference-FINAJ.

15. Roberts M. Tobacco 'kills two in three smokers'. BBC News, 24 February 2015. Available from https://www.bbc.com/ news/health-31600118

16. Bond L, Daube M, Chikritzhs T. Selling addictions: Similarities in approaches between Big Tobacco and Big Booze. AMJ 2010;3(6):325-32. https://doi.org/10.4066/ AMJ.2010.363.

17. Petticrew M, Maani Hessari N, Knai C, Weiderpass E. How alcohol industry organisations mislead the public about alcohol and cancer. Drug Alcohol Rev 2018 Mar;37(3):293303. https://doi.org/10.1111/dar.12596.

18. Agency for Toxic Substances \& Disease Registry (ATSDR) Toxicological Profile for Glyphosate. (Draft for Public Comment). Atlanta, GA: U.S. Department of Health and Human Service; 2019.

19. Morabia A. Fighting independent risk assessment of talc and glyphosate: whose benefit is it anyway? [editorial]. Am J Public Health 2019 Jul;109(7):955-6. https://doi. org/10.2105/AJPH.2019.305144.

20. Samet JM. Expert review under attack: glyphosate, talc, and cancer [editorial]. Am J Public Health 2019 Jul;109(7):9768. https://doi.org/10.2105/AJPH.2019.305131.

21. Vineis P. Public health and independent risk assessment Am J Public Health 2019 Jul;109(7):978-80. https://doi. org/10.2105/AJPH.2019.305142.

22. Steele S, Ruskin G, Sarcevic L, McKee M, Stuckler D. Are industry-funded charities promoting "advocacy-led studies" or "evidence-based science"?: a case study of the International Life Sciences Institute. Globalization and Health 2019; 15: 36-44. https://globalizationandhealth.biomedcentral.com/ track/pdf/10.1186/s12992-019-0478-6

23. Neslen A. UN/WHO panel in conflict of interest row over glyphosate cancer risk. The Guardian. 2016. Available from: https://www.theguardian.com/environment/2016/may/17/ unwho-panel-in-conflict-of-interest-row-over-glyphosatescancer-risk. [Accessed June 2, 2019].
24. The EC's Group of Chief Scientific Advisors: EU authorisation processes of plant protection products. Scientific Opinion 5/2018. Brussels: European Commission Unit RTD, Scientific Advice Mechanism.

25. Infante PF, Melnick R, Vainio H, Huff J. Commentary: IARC Monographs Program and public health under siege by corporate interests. Am J Ind Med 2018 Apr;61(4):27781. https://doi.org/10.1002/ajim.22811.

26. Rosenblatt J, Mulvany L, Waldman P. EPA Official Accused of Helping Monsanto "kill" Cancer Study. Bloomberg. 2017: March 14. Available from: https://www.bloomberg.com/ news/articles/2017-03-14/monsanto-accused-of-ghostwriting-papers-on-roundup-herbicide-cancer-allegations/.

27. Monsanto lawsuit document 189, case 3-16-md-02741. Filed 3/14/17.

28. US EPA. Glyphosate issue Paper: Evaluation of Carcinogenic Potential.EPA's Office of Pesticide Programs. 2016; Sept 12. Available from: https://www.epa.gov/sites/production/ files/2016-09/documents_issue_paper_evaluation_of carcinogenic_potential.pdf.

29. US EPA. Proposed Interim Registration Review Decision and Responses to Public Comments for Glyphosate. 2019. Available from: https://www.epa.gov/ingredients-usedpesticide-products/glyphosate.

30. Sass J. Regulatory failures $=$ Superweeds and Glyphosate Cancers. Expert blog. April 11, 2019. Available from: https:// www.nrdc.org/experts/jennifer-sass/regulatory-failuressuperweeds-and-glyphosate-cancers.

31. Wikipedia. 2019. Duty of Loyalty. Corporations. Fifth Edition. Examples and Explanations. Alan R. Palmiter. ASPEN. Retrieved 2009-03-17.

32. Gilmore AB, Savell E, Collin J. Public health, corporations and the new responsibility deal: promoting partnerships with vectors of disease? [editorial]. J Public Health (Oxf) 2011 Mar;33(1):2-4. https://doi.org/10.1093/pubmed/fdr008.

Received for publication: 6 June 2019

Harri Vainio, MD, PhD ${ }^{1}$

1 Department of Environmental and Occupational Health, Faculty of Public Health, Kuwait University, Kuwait.

Correspondence to: Prof. Harri Vainio, Faculty of Public Health, Kuwait University, P.O. Box 24923, Safat, 13110 Kuwait. [Email: Harri.Vainio@hsc.edu.kw] 